\title{
Artefactual ST segment abnormalities due to electrocardiograph design
}

\author{
D I TAYLER, R VINCENT \\ From the Royal Sussex County Hospital, Brighton
}

SUMMARY Specifications recommended for electrocardiographs omit any reference to phase characteristics and place undue emphasis on an extended amplitude response. This does not, however, ensure faithful reproduction of the electrocardiogram and may result in less effective attenuation of unwanted noise than can be achieved with modern filters. The separate effects of phase and amplitude response on electrocardiographic signals were compared, and it was shown that distortion of the electrocardiogram by equipment with an inadequate phase response may cause changes resembling those seen in ischaemic heart disease. Case reports are presented in which distortion produced by commercial equipment impeded diagnosis. Specifications recommended as standard for electrocardiographs should be modified to include phase response and allow greater attenuation of frequencies below $0.5 \mathrm{~Hz}$.

The surface electrocardiogram is derived from signals that are small, complex, and often contaminated with electrical noise. Recording devices must include amplifiers and filters, but both may produce unwanted distortion unless carefully designed.

Although the electrocardiogram is a complex signal of irregular shape, it is usually repetitive. It may therefore, like any repetitive signal, be expressed as the sum of a series of simply related sine waves (Fig. 1 (a)). If it is to be recorded without distortion its component sine waves must be amplified equally - that is, a machine must have an unvarying (or flat) amplitude response over the range of frequencies present in the signal. This alone, however, does not ensure faithful reproduction. It is also necessary that all components passing through the recorder should be delayed by the same amount. An equal delay of all component sine waves is achieved when the machine has a linear phase response over the required frequency range. If the phase response is non-linear components of the $Q R S$ complex will be delayed selectively and distortion will result.

Filters can be used to eliminate noise without introducing distortion only if the frequency spectrum of the noise differs substantially from that of the

Requests for reprints to Dr R Vincent, Department of Cardiology, Royal Sussex County Hospital, Brighton, Sussex BN2 5BE.

Accepted for publication 2 April 1985 signal. An ideal filter attenuates noise considerably but has no effect on signals in the required passband. Baseline drift and respiratory artefact are at lower frequencies than the electrocardiogram. Muscle tremor has a range of frequencies overlapping the wanted signal, and a power line noise has a frequency that is higher than many contained in the electrocardiogram. Thus power line noise and baseline drift may be reduced or eliminated by filtering whereas muscle tremor can be reduced only slightly.

To define standards for the design of amplifiers and filters we investigated separately the effects of an imperfect amplitude response and a non-linear phase response on normal and abnormal tracings. We also analysed the electrical characteristics of several commercially available electrocardiographs and monitors to show that equipment in routine clinical use may fail to meet these standards and may prevent accurate diagnosis.

\section{Methods and results}

Four methods were used to investigate the effects of a restricted amplitude response and phase non-linearity on electrocardiographic recordings.

Method 1-The constituent frequencies of 50 normal electrocardiographic signals were obtained using Fourier analysis. The effect of different filters on these signals was then simulated by changing the amplitude of individual frequencies or introducing phase 

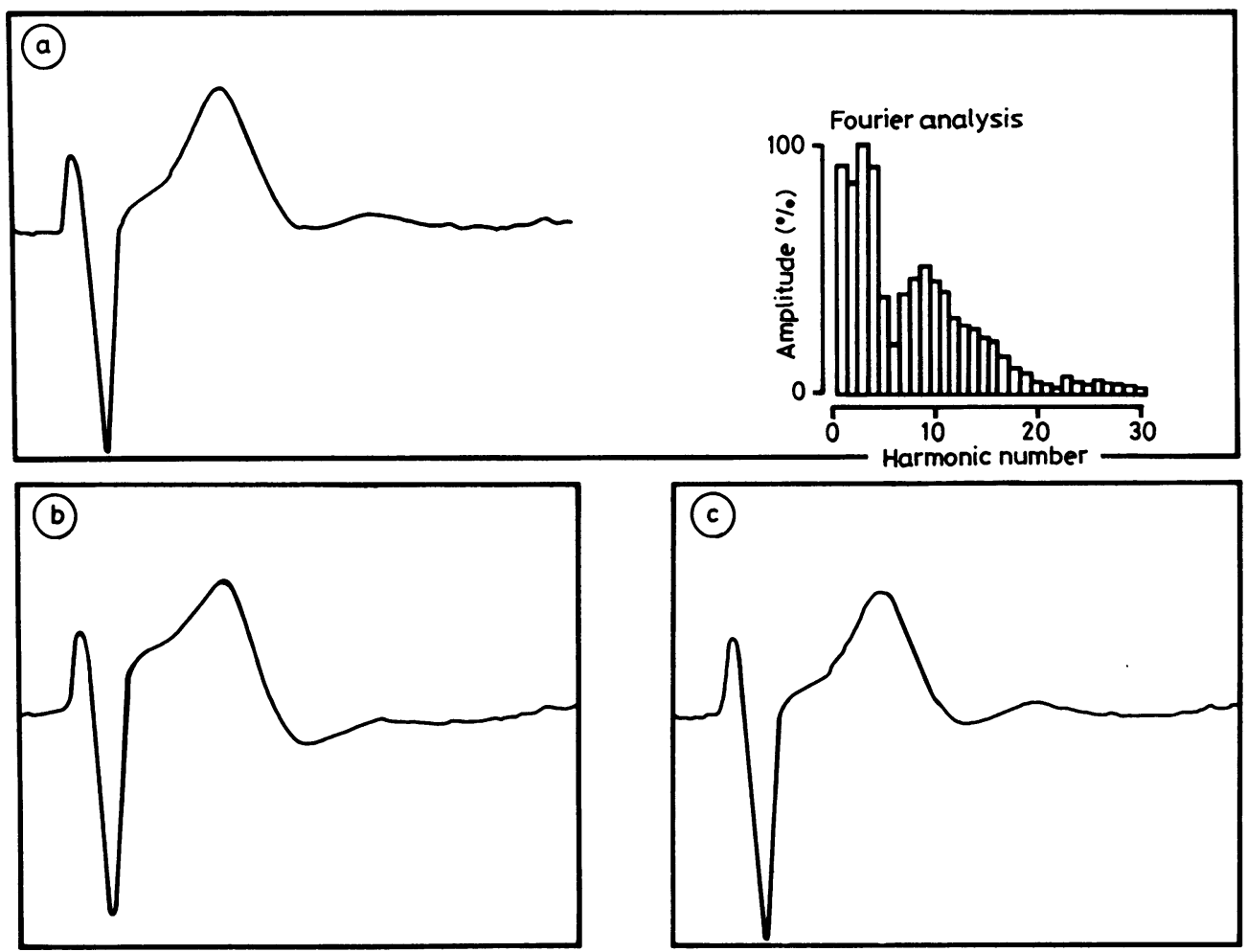

Fig. 1 (a) A typical electrocardiographic complex together with its Fourier analysis. If the heart rate is 60 beats /min then harmonic no 1 corresponds to a sinewave of $1 \mathrm{~Hz}$, no 2 to $2 \mathrm{~Hz}$, etc, up to $30 \mathrm{~Hz}$. (b) The same complex with delayed low frequency components (note ST segment elevation). (c) The same complex with a 20\% atternation in amplizude at $1 \mathrm{~Hz}$ and a $10 \%$ reduction at $2 \mathrm{~Hz}$. Little change in shape results, just a smaller $T$ wave.

delays before reconstructing each waveform from its components.

Method 2-A circuit with an ideal amplitude response but a non-linear phase response (an all pass filter) was constructed to investigate the distortion of the electrocardiogram caused by phase non-linearity alone.

Method 3-The phase and amplitude characteristics of three ambulatory recorders, two electrocardiographs, and one monitor and recorder available commercially were determined, and the resulting signal distortion was noted.

Method 4-The recorders of two machines under study were modified by improving their phase response to reduce the distortion.

\section{FOURIER ANALYSIS AND COMPUTER MODELLING} (METHOD 1)

As the electrocardiogram is a repetitive signal it may be regarded as a Fourier series or the sum of a series of sine waves related harmonically. ${ }^{1}$ We estimated the size of the individual sine waves forming 50 different electrocardiograms by breaking each waveform into its components using a fast Fourier transform algorithm and a microcomputer. A typical electrocardiographic waveform (lead V2) together with its Fourier analysis is shown in Fig. 1(a). The lowest frequency present is the reciprocal of the $R R$ interval. $T$ wave information is also of low frequency, $<10 \mathrm{~Hz}$, and the QRS complex has most of its energy in frequencies below $30 \mathrm{~Hz}$.

After transforming the waveforms into their frequency components we were able to investigate the effect of filtering on the original electrocardiogram by changing the magnitude and delay (or relative phase angle) of individual harmonics or groups of harmonics. Once modified, the frequency components were reassembled using the microcomputer and the results compared with the original waveform (Figs. 1(b) and $1(c))$.

Phase delays of the lower frequency components caused errors, predominantly in the ST segment. As 
the ST segment is particularly important for the diagnosis of ischaemic heart disease we divided it into four and measured the mean and maximum distortion for each section. The amount of distortion produced depended on the degree of non-linearity introduced and the amplitude of the low frequency harmonics in the original signal. Waveforms with large $T$ waves and ST segment elevation or depression were distorted more than waveforms with small $\mathrm{T}$ waves and isoelectric ST segments. Low frequency delays (or phase lags) produced early ST segment elevation and terminal $T$ wave inversion in leads with a dominant $S$ wave-for example, the anterior chest leads (Fig. 1(b)) - and plane ST segment depression in leads with a dominant $R$ wave.

In contrast, the waveform was insensitive to changes in amplitude response and attenuation of low frequency components without phase changes resulted only in a loss of $\mathrm{T}$ wave amplitude. An attenuation of $20 \%$ in amplitude of the first harmonic caused less than $0.05 \mathrm{mV}$ distortion (Fig. 1(c)).

THE ALL PASS FILTER (METHOD 2)

The independent effect of phase and amplitude response was also shown by passing electrocardiographic signals through an "all pass" filter. This device had a uniform amplitude response but a nonlinear phase response, passing low frequencies with a longer delay than high ones. When incorporated into the electrocardiograph this circuit produced ST changes resembling those of myocardial injury (Fig. 2). The modified machine still met the American Heart Association's specification for the frequency response of electrocardiographs.
PHASE RESPONSE OF COMMERCIALLY AVAILABLE MACHINES (METHOD 3)

We evaluated the phase and amplitude characteristics of three ambulatory recorders, two electrocardiographs, and one defibrillator/monitor, which had been modified by the manufacturer to perform a 12 lead electrocardiogram.

The amplitude response of a hard copy electrocardiographic recorder is easy to determine: a sine wave of variable frequency but fixed magnitude ( $1 \mathrm{mV}$ peak to peak) may be applied to the input of the device and the usual pen recorder used to draw the output on paper. The relative amplitude of the inscribed trace for different input frequencies can then be plotted. Phase response is more difficult to measure as the output of a recording system, a line on paper, is of different physical form from the input signal, an electrical voltage. In ambulatory recordings the time separation and the difference in the speed of the tape between recording and replaying further complicate the measurement of phase response.

To overcome these problems phase was measured using the technique described by Wagner. ${ }^{2}$ The input signal was formed from a sine wave and its third harmonic. If the system under test had a linear phase response both frequencies would be delayed by the same amount and the output would not be distorted. If there was phase non-linearity distortion would occur. Measurement of the resulting distortion indicated the phase response of the device. ${ }^{3}$

Results for the machines that we assessed are shown in the Table, and responses for the ambulatory monitors appear in Fig. 3. The peak in amplitude response at $0.3-0.5 \mathrm{~Hz}$ by the recorders that used the
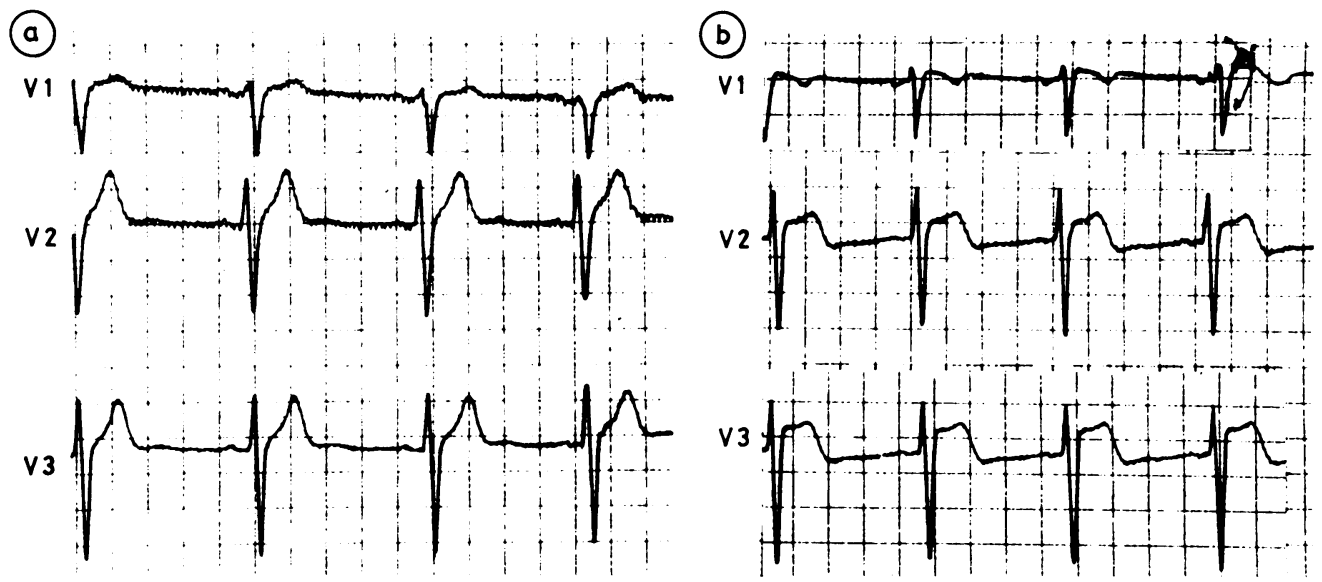

Fig. 2 (a) An electrocardiographic signal recorded without phase delay, and (b) the same signal with phase distortion but with amplitude response unchanged. 
Table Characteristics of electrocardiographs tested

\begin{tabular}{|c|c|c|c|c|c|}
\hline & $\begin{array}{l}\text { Claimed to meet } \\
\text { AHA's } \\
\text { specification }\end{array}$ & $\begin{array}{l}\text { Measured } \\
\text { amplitude } \\
\text { response }\end{array}$ & $\begin{array}{l}\text { Phase } \\
\text { response }\end{array}$ & $\begin{array}{l}\text { Electrocardiogram } \\
\text { distortion }\end{array}$ & $\begin{array}{l}\text { Baseline } \\
\text { stability }\end{array}$ \\
\hline \multirow{2}{*}{$\begin{array}{l}\text { Electrocardiographs: } \\
\text { VS4 (Cambridge) } \\
\text { Mingograf Minor (Siemens } \\
\text { Elema) } \\
\text { Ambulatory recorders: }\end{array}$} & Yes & To AHA's specification & Satisfactory & None & Poor \\
\hline & Yes & To AHA's specification & Satisfactory & None & Poor \\
\hline $\begin{array}{l}\text { Medilog I/PBI (Oxford } \\
\text { Instruments) }\end{array}$ & No & $\begin{array}{l}\text { Peak at } 0.4 \mathrm{~Hz} \text {, rapid } \\
\text { low frequency fall off }\end{array}$ & Poor & Pronounced & Satisfactory \\
\hline $\begin{array}{l}\text { Medilog II/PB4 (Oxford } \\
\text { Instruments) }\end{array}$ & Yes & $\begin{array}{l}\text { To AHA's specification } \\
\text { at low frequencies }\end{array}$ & Satisfactory & Loss of $R$ wave & $\begin{array}{l}\text { Fair (wave an } \\
\text { noise) }\end{array}$ \\
\hline $\begin{array}{l}\text { Tracker/RP II (Reynolds } \\
\text { Medical Electronics) }\end{array}$ & Yes & $\begin{array}{l}\text { Peak at } 0.3 \mathrm{~Hz} \text {, rapid } \\
\text { fall off (see Fig. } 3 \text { ) }\end{array}$ & $\begin{array}{l}\text { Satisfactory } \\
\quad \text { (see Fig. 3b) }\end{array}$ & $\begin{array}{l}\text { Some } R \text { wave } \\
\text { attenuation }\end{array}$ & Poor \\
\hline $\begin{array}{l}\text { Monitor/Defibrillator: } \\
\text { DMS } 600 \text { (Simonsen and } \\
\text { Weel) }\end{array}$ & No & $30 \%$ down at $0.5 \mathrm{~Hz}$ & Poor & Pronounced & Satisfactory \\
\hline Meddars Diagnostic & Yes & To AHA's specification & Satisfactory & None & Poor \\
\hline
\end{tabular}

$\star$ Phase response was satisfactory if the non-linearity was less than $6^{c}$ over the physiological range of frequencies or poor if the non-linearity produced appreciable distortion of the electrocardiogram.

AHA, American Heart Association.
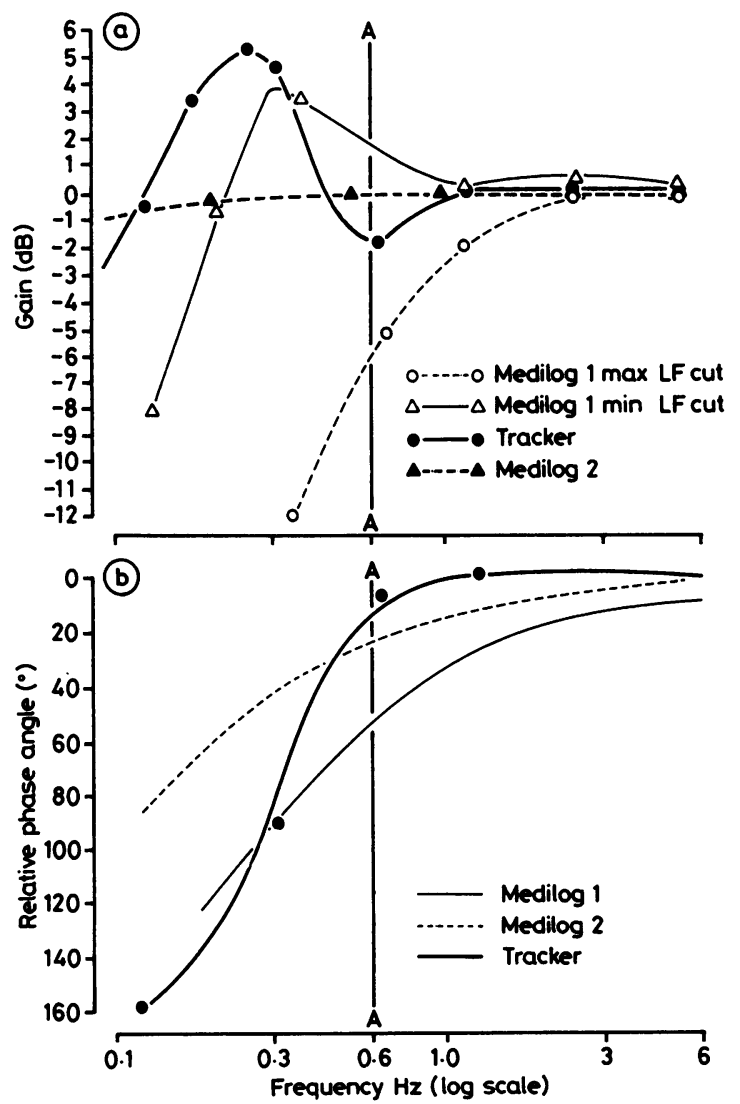

Fig. 3 (a) Amplitude response and (b) relative phase response for three ambulatory recorders. $L F$, low frequency. direct recording method (Tracker and Medilog 1) was due to mechanical design of the tape replay heads and increased recorded noise, such as respiratory artefact, at this frequency. This occurred despite one manufacturer claiming that his machine met the American Heart Association's specification. ${ }^{4}$ The recorder amplifiers may have met this specification, but the overall record replay system did not. The amplitude response of the electrocardiographs and the Medilog II/PB4 recorder system met the American Heart Association's specification, though some examples of the Medilog II produced excessive electrical noise, which made ST segment shifts difficult to measure. Phase distortion began to occur with all machines at frequencies within the physiological range, above A-A (Fig. 3(b)), but was most noticeable with the Medilog I and the DMS 600.

\section{MODIFICATION OF RECORDERS TO REDUCE DISTORTION (METHOD 4)}

The distortion produced by the Medilog I/PB1 system was reduced by modifying its phase response. This was achieved in two ways. Firstly, a phase compensating network was inserted after the replay amplifier. This reduced distortion (Fig. 4) but increased low frequency amplification and so impaired baseline stability. Secondly, the tape was replayed backwards. Low frequency components that had suffered delays in recording were similarly delayed in the opposite direction on replay thus noticeably reducing phase distortion. ${ }^{5}$ The amplitude response was unchanged by this procedure, which resulted in a great improvement in recording quality (Fig. 4) but made timing of events difficult. 


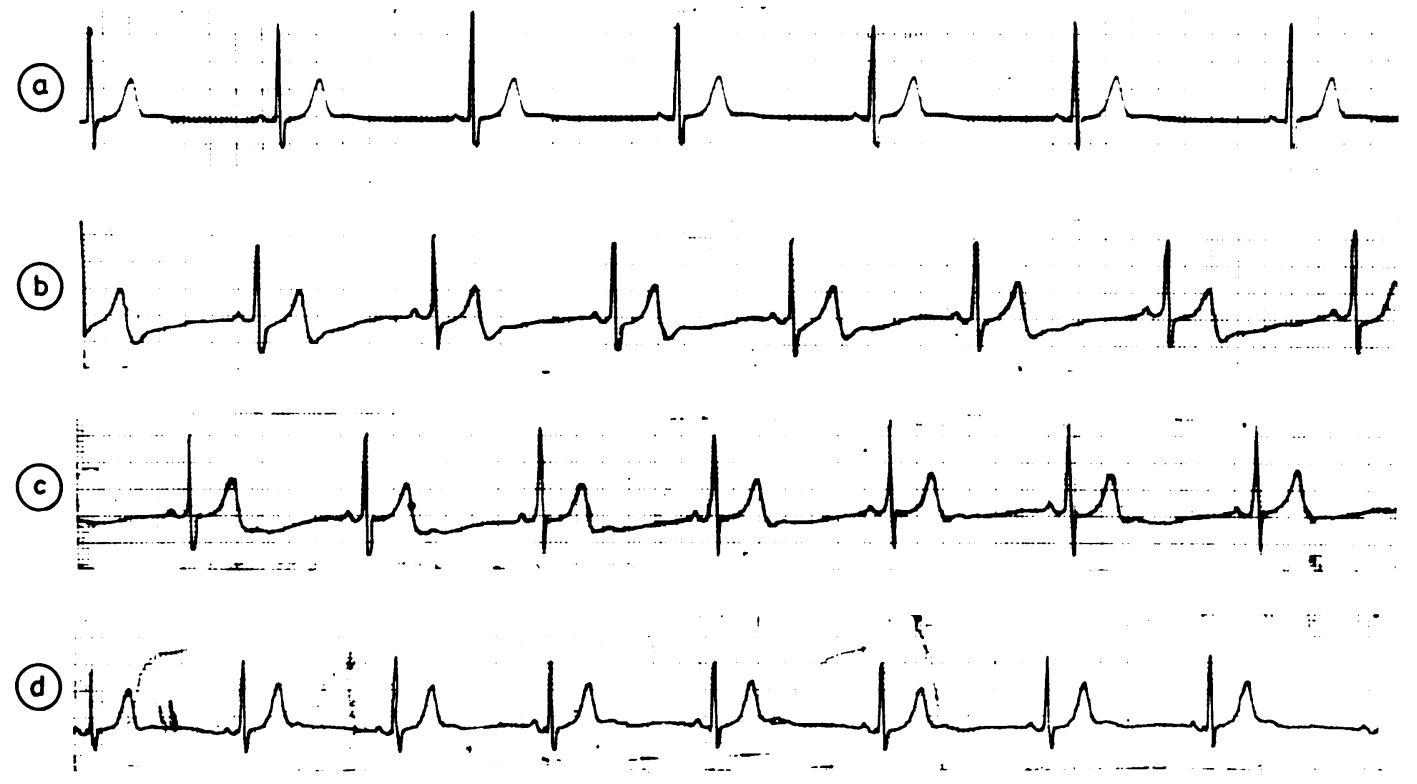

Fig. 4 Effect of phase distortion on electrocardiograms (a) recorded on a high quality electrocardiograph, (b) with the same signal recorded on a Medilog 1, (c) recorded on a Medilog 1 with phase correction, and (d) recorded on a Medilog 1 with the tape replayed backwards and inverted. Replaying the tape backwards had no effect on amplitude response but improved the phase response. (Copyright (C) 1983 IEEE.)

The phase response of the DMS 600 monitor was also improved by circuit changes made by the manufacturers. These changes reduced distortion but impaired low frequency stability by allowing the amplification of unwanted noise.

\section{Case reports}

The DMS 600 defibrillator/monitor analysed above has been carried by resuscitation ambulances in the Brighton area since 1973. Although primarily a high performance arrhythmia monitor, it is capable of recording a full 12 lead electrocardiogram. (A diagnostic trace recorded before admission to hospital can show important changes that are absent on later records.) We have, however, observed several instances of artefactual ST segment elevation or depression in electrocardiograms recorded by this machine. These artefacts simulated changes seen in disease states, led to additional investigations, and made diagnosis difficult. We present six cases in which distortion produced by such a machine impeded diagnosis.

CASE 1

A 33 year old man presented with central chest pain lasting for $\mathbf{4 5}$ minutes. Results of electrocardiography performed in the ambulance showed anterior ST segment elevation. Repeat electrocardiograms in hospital were normal apart from minor lateral $\mathrm{T}$ wave changes, and there was no increase in cardiac enzyme activity. A week later he developed a second attack of pain, again with anterior ST segment elevation shown on the electrocardiograms recorded in the ambulance. Diagnostic quality traces were unchanged (Fig. 5(a)). An exercise stress test was normal with good exercise tolerance and satisfactory blood pressure response and his lateral $\mathrm{T}$ waves had returned to normal. A technetium scan and subsequent coronary angiography were also normal.

Having failed to find any abnormality in the patient we examined the electrocardiograph in the ambulance as described above. In addition, we noted that a computer generated electrocardiogram with isoelectric ST segments suffered distortion when recorded by the unmodified DMS 600. In a further experiment the electrocardiogram of this patient was reconstructed by digitising his hospital recordings and using a MINC computer (Digital Equipment Corporation) to recreate the electrical waveform. The recreated signal was recorded simultaneously by a VS4 electrocardiograph and the DMS 600. Artefactual ST segment changes are clearly visible (Fig. 6). 
(a)

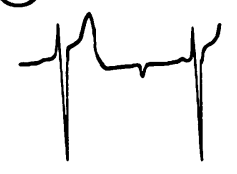

(b)

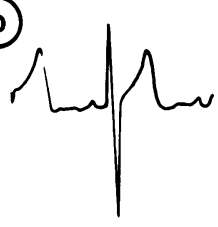

(c)<smiles>CCCCC(C)CCCC</smiles>
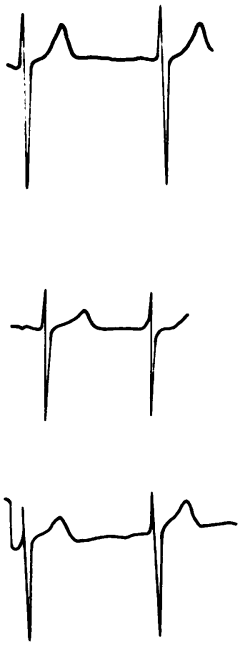

(d)<smiles>CCCCCCCCC</smiles>

(e)<smiles>CCC(C)CC(C)CC(C)C</smiles>

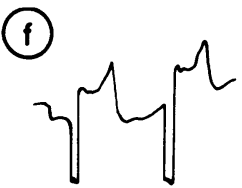
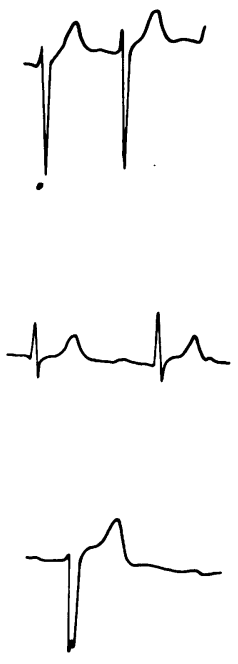

Fig. 5 Anterior complexes recorded fram cases $1-6$ labelled (a) to (f) respectively. The electrocardiogram recorded in the ambulance is shown on the lefi, recordings of diagnostic quality on the right.

CASE 2

A 73 year old woman had suffered from exertional angina for 10 years and hypertension with dizzy spells for one year. On admission her chest pain was relieved by treatment with glyceryl trinitrate; she then col-

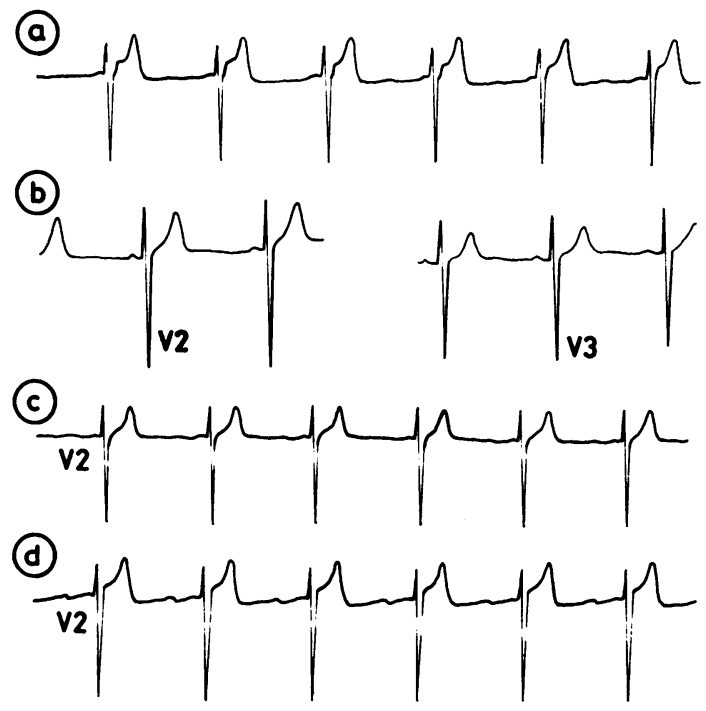

Fig. 6 Electrocardiograms recorded (a) in the ambulance, (b) in casualty, (c) reformed and recorded on VS4, and (d) reformed and re-recorded on the ambulance machine showing ST segment distortion produced by the DMS 600 electrocardiograph. (c) and (d) are simultaneous recordings of the same signal performed on different machines. lapsed. The electrocardiogram taken in the ambulance showed ST segment elevation in leads V2 and V3 and ST segment depression in the lateral chest leads (Fig. 5(b)). A repeat trace one hour later by a diagnostic quality electrocardiograph was normal apart from left axis deviation and plane ST segments in V5 and V6. Physical examination was normal except for mild hypertension. No increase in cardiac enzyme activity was seen. An erroneous diagnosis of Prinzmetal's angina was made initially in this patient.

\section{CASE 3}

A 35 year old man developed a sudden attack of chest pain while sitting an important examination. The pain radiated to his throat and was associated with parasthesiae in his left arm. There was no relevant medical or family history. Physical examination was normal. The electrocardiogram taken in the ambulance showed ST segment elevation in the anterior leads, but subsequent inpatient electrocardiograms were all normal (Fig. 5(c)). An exercise stress test was normal, and a gated technetium scan showed normal wall motion with an ejection fraction of $53 \%$.

\section{CASE 4}

A 34 year old man developed pain over his left chest radiating to his left arm while lifting a heavy girder. He drank three quarters of a bottle of gin with no relief. On examination he had a tender chest wall, and the pain was reproduced by external rotation of his arm. The electrocardiogram taken in the ambulance showed ST segment elevation in the anterior leads 
with lateral ST segment depression. The trace taken in the accident and emergency department was normal (Fig. 5(d)).

\section{CASE 5}

A 73 year old man with hypertension had a 12 hour history of episodes of pain relieved by treatment with glyceryl trinitrate. Physical examination was normal apart from mild hypertension $(160 / 80 \mathrm{~mm} \mathrm{Hg})$. The electrocardiogram recorded in the ambulance showed ST segment elevation in the anterior leads (Fig. 5(e)). The trace recorded in the accident and emergency department showed inferior ischaemia only. Cardiac enzyme activity and results of other routine biochemical tests were normal, and an exercise stress test showed further inferior ischaemia with no anterior changes.

\section{CASE 6}

A 65 year old man was diagnosed as having aortic valve disease in 1979. As his angina and dyspnoea worsened he was entered on a waiting list for cardiac catheterisation. On admission he had experienced severe chest pain, which had not been relieved by treatment with sublingual nitrates. An electrocardiogram recorded in the ambulance showed ST segment elevation; the trace recorded in the accident and emergency department was normal. We.immediately repeated the recording using the machine in the ambulance and again produced artefactual ST segment elevation (Fig. 5(f)). Cardiac enzyme activity failed to show a diagnostic increase.

\section{Discussion}

It is important that diagnostic equipment should give reliable information with minimal chance of error. There should be no need to question whether the information is an artefact or real. It is also important both that the performance of equipment is defined and that manufacturers' claims of function and accuracy are validated.

We investigated the effect of a non-linear phase response on the electrocardiogram both theoretically, with computer modelling and an all pass filter, and in practice, with ambulatory recorders and a monitor defibrillator. We showed that phase distortion may cause electrocardiographic changes similar to those seen in disease states and that this may cause difficulties in diagnosis. Only by repeating recording signals, as in cases 1 and 6 , could we prove that the electrocardiographic changes seen in the six cases were not due to transient myocardial ischaemia; but the observations in all are persuasive.

The effect of filtering on the electrocardiogram was investigated by Pipberger et al, Berson and Pip- berger, and Meyer, ${ }^{6-8}$ and this work led to the current American Heart Association's recommendation for electrocardiographs. ${ }^{9}$ They used simple analogue filters and did not attempt to separate amplitude and phase effects. Current standards specify that the gain of the machine should be substantially constant down to $0.14 \mathrm{~Hz}$, should be not less than $30 \%$ of the midfrequency gain at $0.05 \mathrm{~Hz}$, and should fall only slowly at lower frequencies. Unfortunately, these recommendations make no mention of phase response, and, as we have shown, it is possible to build circuitry that will meet these specifications but will still produce gross distortion of the electrocardiogram.

The extended amplitude response at low frequencies suggested by the American Heart Association does not allow effective attenuation of low frequency noise such as respiratory artefact. This causes difficulty when monitoring active subjects or in electrically noisy situations such as the catheter laboratory. As the electrocardiogram is repetitive it should contain no frequencies lower than the reciprocal of the $R R$ interval. Several authors support this view, ${ }^{10-12}$ and Hyndman produced experimental evidence to suggest that there are no components in a normal electrocardiogram with frequencies lower than $0.5 \mathrm{~Hz} .{ }^{13}$ Our results using the all pass filter confirm this opinion.

Simple analogue filters produce phase distortion at frequencies up to 10 times greater than those at which significant amplitude attenuation occurs. The American Heart Association therefore specifies a frequency of $0.05 \mathrm{~Hz}$ for the $30 \%$ amplitude attenuation point in an attempt to ensure minimal phase distortion at 0.5 $\mathrm{Hz}$ and above. Equipment contains more than simple filters, however, and it is naive to suggest that by specifying such an amplitude characteristic the phase response will necessarily be linear over the physiological range. Indeed the all pass filter will have no effect on the amplitude response but may produce gross distortion of electrocardiographic signals. Phase distortion is particularly serious as it causes changes resembling ischaemia. Moreover, these changes may not always be present as they depend on the morphology of the displayed electrocardiogram.

Ambulatory recorders were developed initially for arrhythmia monitoring and only later used for ST segment analysis. In arrhythmia monitoring $P$ waves and $Q R S$ complexes are of prime consideration, and $T$ wave fidelity may be sacrificed to achieve a stable baseline in ambulatory subjects. Several of the recorders have been criticised when used to monitor ST segments, ${ }^{14}$ and Bragg-Remschel et al reviewed several different types showing many with pronounced phase non-linearity and peaks in their amplitude responses. ${ }^{15}$

The electrocardiograph that distorted the traces of 
our patients had an amplitude response that had decreased by $30 \%$ at $0.5 \mathrm{~Hz}$. This decrease on its own would have caused less than $0.02 \mathrm{mV}$ distortion of the ST segment, but the phase response was noticeably non-linear at frequencies contained within patients' electrocardiograms. It was therefore phase effects that caused the distortion rather than a poor amplitude response.

In analogue filters phase and amplitude responses are often linked but digital filters using microprocessor techniques can be designed with both a linear phase response and amplitude characteristics that provide superior noise reduction. ${ }^{16} 17$

We propose that an ideal electrocardiograph should have the following characteristics: (a) flat amplitude response from $0.5 \mathrm{~Hz}$ to $75 \mathrm{~Hz}$ (to cover the physiological range of frequencies); (b) no response below this frequency to minimise noise; and $(c)$ linear phase response from $0.5 \mathrm{~Hz}$ to $75 \mathrm{~Hz}$. This ideal is impossible to realise at present, but the specifications for electrocardiographs, including the International Electrotechnical Commission draft specification, ${ }^{18}$ should be changed in order to encourage future developments. Several electrocardiographs do incorporate digital filtering and at least two of them claim to have a phase response that is linear.

An extended amplitude response should not be relied upon in an attempt to ensure phase linearity over the physiological range. A more limited amplitude response improves baseline stability and need not increase distortion provided the phase response is satisfactory. We have insufficient data to recommend guidelines for the magnitude of the variation allowed from the ideal linear phase response. Nevertheless, both phase and amplitude responses of a recorder should be specified as the phase reponse of an electrocardiograph is as important, if not more so, than its amplitude response.

We thank patients and staff at the Royal Sussex County Hospital, Brighton, for their cooperation, and Dr D A Chamberlain, Dr D J Woollons, and Dr M J English for their helpful advice. DIT received support from the British Heart Foundation as junior research fellow for much of this study. Fig. 4 is reproduced by kind permission of the Institute of Electrical and Electronics Engineers, Inc.

\section{References}

1 Richardson JM, Murthy VK, Haywood LJ. The effect of random frequency modulation on ECG power spectra. IEEE Trans Biomed Eng 1979; 26: 109-12.

2 Wagner JW. A simple test for phase characteristics of chart recorders. IEEE Trans Biomed Eng 1979; 26: 505-8.

3 Tayler DI, Vincent R. Signal distortion in the electrocardiogram due to inadequate phase response. IEEE Trans Biomed Eng 1983; 30: 352-6.

4 Reynolds Medical. Advertising material for Tracker tape recorder. Eur Heart $f$ 1982; 3: inside back cover.

5 Longini RL, Giolma JP, Wall C, Quick RF. Filtering without phase shift. IEEE Trans Biomed Eng 1975; 22: 432-3.

6 Pipberger HV, Baule G, Berson AS, et al. Recommendations for standardisation of instruments in electrocardiography and vectorcardiography. IEEE Trans Biomed Eng 1967; 14: 60-8.

7 Berson AS, Pipberger HV. The low-frequency response of electrocardiographs, a frequent source of recording errors. Am Heart $\mathcal{F}$ 1966; 71: 779-89.

8 Meyer JL. Some instrument-induced errors in the electrocardiogram. $¥ A M A$ 1967; 201: 351-6.

9 American Heart Association Committee on Electrocardiography. Recommendations for standardization of leads and specifications for instruments in electrocardiography and vectorcardiography. Circulation 1975; 52: 11-31.

10 Murthy VK, Haywood JL, Richardson J, et al. Analysis of power spectral densities of electrocardiograms. Mathematical Biosciences 1971; 12: 41-51.

11 Favret AG, Caputo AF. Evaluation of autocorrelation techniques for detection of the fetal electrocardiogram. IEEE Trans Biomed Eng 1966; 13: 37-43.

12 Golden DP, Wolthius RA, Hoffler GW. A spectral analysis of the normal resting electrocardiogram. IEEE Trans Biomed Eng 1973; 20: 366-72.

13 Hyndman BH. Distortion of the temporal display of the electrocardiogram by analog filtering. Sacramento: California State University, 1972. MS Thesis.

14 Balasubramanian V, Lahiri A, Green HL, Stott FD, Raftery EB. Ambulatory ST segment monitoringproblems, pitfalls, solutions and clinical application. $\mathrm{Br}$ Heart $\mathcal{F}$ 1980; 44: 419-25.

15 Bragg-Remschel DA, Anderson CM, Winkle RA. Frequency response characteristics of ambulatory ECG monitoring systems and their implications for ST segment analysis. Am Heart $\mathcal{f}$ 1982; 103: 20-31.

16 Fukada Denshi Co. Analogue filter system. British Patent No 1556512, December 1976.

17 Lynn PA. Transversal resonator digital filters: fast and flexible online processors for biological signals. Med Biol Eng Comput 1983; 21: 718-30.

18 Technical Committee LEL/103. Medical electrical and radiological equipment. Draft standard specification for the performance of single channel and multichannel electrocardiographs. (IEC 62D (Central Office) 6) 1978. 